\section{Questión}

Periodismo / Comunicación ISSN 1669-6581
- Av. $44 \mathrm{~N}^{\circ} 676,1^{\circ}$ piso

CP 1900 - La Plata - Argentina

www.perio.unlp.edu.ar/question

Cuarentena temporada 2

Paloma Barberena Rivas

DOI: https://doi.org/10.24215/16696581e346

\title{
Cuarentena temporada 2
}

\section{Quarantine season 2}

\author{
Paloma Barberena Rivas \\ Estudiante avanzada de la Licenciatura y el Profesorado en Comunicación Social. \\ Facultad de Periodismo y Comunicación Social \\ Universidad Nacional de La Plata \\ Está realizando su Trabajo Integrador Final. \\ Es productora de Radio Universidad de La Plata \\ Fue colaboradora de Diario Contexto y de la Revista La Fragua \\ palomabarberenarivas@gmail.com
}

\section{Palabras claves}

Encierro - Extrañamiento- Comunicación

\section{Key words}

Running of the bulls - estrangement - communication

El tiempo está pasando y eso afecta no solo nuestra salud mental sino también los hechos cotidianos. No es lo mismo vivir aisladx un lapso determinado y saber cuándo empieza y cuando termina que pasar más días del año encerradxs que sin estarlo. Las primeras semanas fueron una situación de asombro: charlas mientras las personas cocinaban, otras para merendar, algunas de noche simulando una salida, hoy quizá esto no desapareció por completo, si el efecto de extrañeza.

-Son quince días, chicas. En algún otro momento pasamos más tiempo sin vernos.

Me acuerdo el día que vi a las chicas por última vez, fue el 17 de marzo. En esa época se hablaba poco, al menos en mi grupo, de la extensión de la cuarentena. Las más optimistas 
creíamos que no se alargaría: "o no mucho más", por la economía y la salud mental. Otras, más realistas, la veían para rato: "para mi hasta mayo seguimos así".

La pandemia que le toca vivir al mundo entero no tiene precedentes históricos, es nueva para todxs: para los gobiernos, para las empresas, para los medios de comunicación, para Ixs ciudadanxs. Desde el comienzo de la cuarentena en nuestro país, a mediados de marzo, se crearon y difundieron diversas reflexiones, distintos consejos para atravesarla y variados análisis respecto a la misma. Aún no se pueden nombrar los efectos de esto ni del virus porque todavía no son tangibles, estamos atravesando la situación. No podemos distanciarnos, mirar el escenario desde la lejanía. Es complicado teorizar con ella, concluir algo, entenderla.

Parafraseando al pensador, Ignacio Lewkowicsi podemos nombrar a la subjetividad como los modos de ser y hacer de una sociedad en una época: es el conjunto de operaciones que se realizan para habitar un dispositivo, una situación, un mundo. Hoy nos encontramos en un momento donde hay que trabajar para el reacomodamiento de la subjetividad porque las prácticas, los modos y las rutinas se ven modificadas. Las personas están generando herramientas para atravesar esta realidad nueva que aún no tiene final aparente.

La psicóloga, Alexandra Kohan se preguntó en una entrevista para la revisa Mate: “¿Cómo se podría leer, escribir, terminar la tesis, ordenar el placard, "aprovechar", si el mundo, tal y como lo habitamos hasta hoy, ya no está más ahí? Me parece muy complicado intentar armar escenarios como si nada estuviera pasando, como si todo ifuera igual pero dentro de casa. Una cosa va con la otra: no hubo tiempo para advertir qué es esto y por eso todos los imperativos terminaron siendo negadores de un real que nos está afectando indefectiblemente y cuyos efectos aún son incalculables". Esta nota fue publicada el 24 de marzo de este año, a cinco días del comienzo de la cuarentena obligatoria.

Cuando la leí, repito, a principios del confinamiento me sirvió para pensarme en la cuarentena, para alivianar la culpa medio cristiana, medio capitalista que me generaba no seguir a esxs influencers, por ejemplo, que proponían en sus perfiles cocinar masa madre o hacer rutinas de ejercicios. Sobre todo, me tranquilizaba pensar que tenía todo el sentido del mundo no encontrar motivación para terminar, en mi caso, una responsabilidad como la producción de la tesis o practicar un hobbie que debería resultar gozoso como los cuentos que tiempo atrás había comenzado a escribir. El artículo trajo tranquilidad a las exigencias individuales sobre el aprovechamiento del tiempo. 
Sirvió para pensar y pasar ese primer momento: pospongamos responsabilidades, total ya se va a terminar. Quiero decir, fueron necesarias esa y otras reflexiones de líderes de opinión, pensadores y especialistas que vinieron a echar luz sobre lo que a todxs nos estaba impacientando y angustiando pero quizá no nos animábamos a decir.

Con esto no busco deslegitimar la palabra de Kohan o decir que quedó obsoleto, para nada. Pienso que es una lectura que sigue teniendo vigencia y verosimilitud pero convive con otras. Creo que eso es lo que este momento propone: generar una visión y luego una revisión una y otra vez de las formas de pensar y hacer.

Una amiga me contó que su mamá le aconsejó, por esa misma época, que a pesar de estar conflictuada no corte con el novio porque "no hay que tomar decisiones en cuarentena". Ellxs habían empezado su relación a mediados de febrero. Hoy, llevan más tiempo "juntxs" en cuarentena que sin ella. Hace pocos días hablamos y ambas concluimos otra reflexión distinta a la inicial: quizá ya sea momento de tomar una decisión.

Hace pocos días hable con alguien de mi familia y noté que en un momento le dije "Ayer me reuní con mi director de tesis y hablamos de un capítulo", un segundo después me di cuenta que no había agregado el sustantivo "zoom" o "videollamada" a la oración. Naturalicé que el encuentro era por estas plataformas. Lo mismo me sucedió charlando con un amigo: le conté que con mis amigas nos reuniríamos para darle un regalo a una del grupo, la que vive conmigo. Él no se sorprendió, podría haber pensado que le estaba contando que iba a romper la cuarentena para ver a mis amigas pero no porque entendió que hablaba de una reunión virtual. Al releer este párrafo noto que las dos veces que usé el verbo hablar (con mi familiar y mi amigo), jamás lo hice acompañando la acción con la palabra Zoom, Skype, Jitsi o Whatsapp.

Antes de escribir este texto, estuve pensando en twitter y haciendo algunas búsquedas. Twitter es hoy, quizá, un espacio para el análisis sociológico o antropológico. Los primeros días del aislamiento, es decir hasta antes del 31 de marzo, en las redes sociales, tomando a esta como ejemplo, todo lo publicado tenía que ver con la cuarentena. Hoy, veo un Twitter más parecido al que conocíamos, al que no estaba dentro de una situación de extrañamiento: discusiones sobre el feminismo, capturas de pantalla que funcionan como pruebas para demostrar algo 0 memes, chismes sobre famosos y anécdotas bizarras, sin necesidad de una vinculación con lo que está pasando. 
Lo mismo noto en algunos programas televisivos de la tarde (uso estos como ejemplo porque los noticieros cumplen otra función). La última tendencia en Twitter Argentina fue la estafa de la empresa de cosméticos NuSkin: Varias famosas jóvenes se filmaron usando una maquinita facial de esta marca que costaba alrededor de $\$ 30.000$. Al otro día de esos videos se comprobó y difundió que tanto el artefacto como el sistema de ventas no era legal.

Unos días atrás, pensando en la nota, hice tres encuestas en mi cuenta personal de Instagram sobre esto. Digo esto, porque no me refiero a la pandemia o al aislamiento, sino al conjunto: esto que aún atravesamos. Hecha la aclaración, continúo. En las encuestas pregunté: Con respecto al primer mes de cuarentena: ¿hacés más o menos videollamadas? Con relación al primer mes de cuarentena: ¿publicás más o menos contenido sobre esta situación en tus redes sociales? En cuanto al consumo de información: ¿consumís más o menos información y actualizaciones del tema? Mis preguntas no tienen rigor científico ni pueden ser tomadas como estadísticas confiables pero me pareció interesante saber si a mi entorno le sucede algo similar a lo que me sucede a mí. En síntesis las respuestas arrojaron, resultados similares para las tres preguntas, sobre un total de 263 votantes: el $\% 70$ de las personas hacen menor cantidad de videollamadas, publican menos contenido vinculado al tema y consumen menos información sobre ello.

Con esto no quiero decir que cambió un paradigma de la cuarentena, sino que el tiempo está pasando y eso afecta no solo nuestra salud mental sino también los hechos cotidianos. No es lo mismo vivir aisladx un lapso determinado y saber cuándo empieza y cuando termina que pasar más días del año encerradxs que sin estarlo. Esas primeras semanas fueron una situación de asombro: charlas mientras las personas cocinaban, otras para merendar, algunas de noche simulando una salida, a veces con familiares contando el día de yoga, estudio, trabajo, limpieza y series. Hoy quizá esto no desapareció por completo pero el efecto de extrañeza si.

El filósofo, Cornelius Castoriadisiii planteó que el imaginario social tiene un doble modo de existir que se define como lo instituido y lo instituyente. Lo instituido son las significaciones que parecen estáticas en las instituciones más arraigadas, más duras. Lo instituyente son las acciones o significaciones que tienen la capacidad de transformar socialmente eso instituido, para convertirse luego en ello. Quizá esta situación no sea comparable porque no implica un 
colectivo, una lucha social, pero sí creo que nuestro imaginario social, nuestra subjetividad, va cambiando con el avance de la pandemia y todo lo que ella conlleva.

A lo largo y ancho del país las fases van cambiando: la mayoría de provincias están en fase cuatro, AMBA -sigla que la mayoría descubrimos estas semanas- sigue en la fase tres; algunas localidades ya habilitaron bares, gimnasios, tiendas de venta de artículos que no son de primera necesidad. Pero hay algo que parece mantenerse igual en toda la Argentina: es muy posible que el ciclo lectivo, en sus distintas instancias educativas, no se retome tal cual como lo conocemos.

Es que si bien hay distintas fases y reglas puede que el cambio haya sido, o deba ser, según mi percepción, claro, entre la procrastinarían y la decisión: La aceptación de que quizá este modo sea el que funcione hasta por lo menos fin de año. Pienso que tal vez sea hora de pasar de de "no tomar decisiones en cuarentena" a "tomar decisiones porque vamos a seguir en cuarentena"; y no escribo esto por la situación amorosa de mi amiga, particularmente, sino, por la situación educativa, por ejemplo.

Quizá tengamos que asumir que nos vamos a recibir en cuarentena o que si bien preferíamos cursar algunas materias de manera presencial para sacarle más jugo o hacer las prácticas debamos renunciar a eso y adaptarnos a un posible segundo cuatrimestre virtual. Y porque no también, decidir sobre esa relación porque la incertidumbre está pesando. No volver a la toma de decisiones sería hacer como si este año no existiera, seria, sencillamente, negar al 2020.

Ya lo aclaré en varias líneas pero va de nuevo: este texto está escrito desde mi perspectiva y reafirmo que no soy quien para aconsejar -menos en una situación donde no se puede comparar con nada- pero creo que quizá retomar alguna de las cosas que conocemos y forman (o formaban) parte de nuestra cotidianeidad, frente a lo desconocido e innombrable, sea algo que pueda resultarnos ameno. Porque la toma de decisiones es algo que nos resulta familiar y nos lleva a lo posible y real: sabemos cómo se hace. Nadie dice que las decisiones conduzcan a buenos resultados pero desde ya puede que el retorno a las prácticas de las que somos habitúes -así sea dentro de un departamento- apacigüe un poco esa angustia indescriptible que se encargaron de poner en primera plana los medios de comunicación.

Hace tres meses no habría hecho esa encuesta por instagram. Me habría gustado hacerla en la calle o a mis amigos en una juntada en una casa, hoy también me gustaría pero antes tenía la posibilidad. La virtualidad hoy es mi herramienta. Esta nota no quiere ser pesimista. Al 
contrario. Creo que en esta nueva subjetividad están surgiendo modos de adaptación para la situación. Nos queda, nomás, ir viendo y haciendo en esta contingencia porque al final pasaron más de quince días desde la última vez que vi a las chicas.

\section{Notas}

\footnotetext{
' Lewkowicz, Ignacio (15 de agosto de 1961 - 4 de abril de 2004) fue un historiador y filósofo argentino dedicado al estudio de la subjetividad contemporánea. https://es.wikipedia.org/wiki/lgnacio Lewkowicz

inEntrevista a Alexandra Kohan realizada por Bautista Veaute https://www.revistamate.com.ar/2020/03/alexandrakohan-el-mundo-nos-silencio-a-nosotros-el-mundo-se-detuvo-y-nosotros-quedamos-pedaleando-en-el-airel

iii CASTORIADIS, Cornelus (2004), Sujeto y verdad en el mundo histórico-socia, Fondo de Cultura Económica. Buenos Aires.
} 